\title{
FARKLI ÇAPLARDAKİ KUM PARTİKÜLLERİ İLE YAPILAN KUMLAMA İŞLEMİNİN İMPLANT-ABUTMENT-REZİN SİMAN BAĞLANMASINA ETKİSİNİN ÇEKME BAĞLANMA TESTİ İLE DEĞERLENDİRİLMESİ

\author{
EVALUATION OF THE EFFECT OF SANDBLASTING WITH DIFFERENT SAND \\ PARTICLES ON THE BONDING OF IMPLANT, ABUTMENT AND RESIN CEMENT BY \\ TENSILE BOND STRENGHT
}

\author{
Dr. Öğr. Üyesi Türker AKAR*
}

Doç. Dr. Ömer KIRMALI**

\author{
Makale Kodu/Article code: 4637 \\ Makale Gönderilme tarihi: 16.10 .2020 \\ Kabul Tarihi: 12.03.2021 \\ DOI : $10.17567 /$ ataunidfd. 895700
}

Türker Akar: ORCID ID: 0000-0003-2035-8686

Ömer Kırmalı: ORCID ID: 0000-0002-4313-344X

\section{öz}

Amaç: Bu çalışmanın amacı, titanyum implant dayanak ile rezin siman arasındaki çekme bağlanma dayanımını araştırmak için farklı boyutlarda kum partiküllerinin etkilerini değerlendirmektir.

Gereç ve yöntem: Kırk adet titanyum implant dayanak seçildi ve farklı yüzey işlemlerine göre; ișlem yapılmamış yüzey (kontrol), $30 \mu \mathrm{m}$ silika kaplı kumlama, $50 \mu \mathrm{m} \mathrm{Al} \mathrm{O}_{3}$ kumlama ve $110 \mu \mathrm{m} \mathrm{Al}_{2} \mathrm{O}_{3}$ kumlama olacak şekilde 4 farklı gruba ayrıldı. Yüzey işlemlerinin ardından bütün implant dayanakları oklüzalinde halka bulunan metal alt yapılara dual cure rezin siman ile simante edildi. 500 termal siklus uygulanan implant dayanak-metal alt yapı örnekleri daha sonra geleneksel kırma cihazında 0,5 $\mathrm{mm} / \mathrm{dk}$ hızda çekme bağlanma kuvvetine tabi tutuldu. Kırılma sonrası kırılma tipleri $(\times 35)$ stereomikroskop ile ve yüzey topografyasındaki değişiklikler ise taramalı elektron mikroskobu (SEM) altında $(\times 1000)$ büyütme ile değerlendirildi. Elde edilen verilerin istatistiksel analizi tek yönlü ANOVA, gruplar arasındaki karşılaştırmalar ise Tukey testi ile yapıldı.

Bulgular: Çalışmanın sonuçlarına göre en yüksek çekme bağlanma kuvveti $30 \mu \mathrm{m}$ silika $(254,42 \pm 13,38)$ grubunda görülürken en düşük çekme bağlanma kuvveti değeri kontrol $(198,24 \pm 15,32)$ grubunda görüldü. Yüzey işlemi uygulanan bütün gruplarda çekme bağlanma kuvveti değerlerinin istatistiksel olarak anlamlı derecede arttığı bulundu.

Sonuç: İmplant-dayanak üzerine uygulanan farklı kum partikülleri, implant dayanak-metal alt yapı arasındaki bağlantı kuvveti de anlamlı derecede farklılıklar gösterdi.

Anahtar kelimeler:Titanyum implant dayanak, $30 \mu \mathrm{m}$ silika, $\mathrm{Al}_{2} \mathrm{O}_{3}$ kumlama, rezin siman, çekme bağlanma dayanımı testi, tarama elektron mikroskobu

\section{ABSTRACT}

Aim: The aim of this study was to evaluate the effects of different sizes of sand particles to investigate the tensile bond strength between titanium implant abutment and resin cement.

Material and Methods: Forty titanium implant abutments were selected. The specimens were divided into 4 different groups according to different surface treatments. These groups are; the untreated surface was named as (control), $30 \mu \mathrm{m}$ silica coated airborne-particle abrasion, $50 \mu \mathrm{m} \mathrm{Al} \mathrm{O}_{3}$ airborne-particle abrasion and $110 \mu \mathrm{m} \mathrm{Al} \mathrm{O}_{3}$ airborne-particle abrasion groups. After surface treatments, all implant abutments were cemented with dual cured resin cement to metal substructures with an occlusal ring. Implant abutment-metal substructure samples, which were applied 500 thermal cycles, were then subjected to tensile bonding strenght at a speed of $0.5 \mathrm{~mm} / \mathrm{min}$ in a conventional crushing device. Post-fracture types of refraction were evaluated with a stereomicroscope $(\times 35)$ and the cause in the surface topography under a scanning electron microscope (SEM) at $(\times 1000)$ magnification. Statistical analysis of the data obtained was made with 1-way ANOVA and comparisons between groups were made by the Tukey post hoc test.

Results: According to the results of the study, the highest tensile bond strength was seen in $30 \mu \mathrm{m}$ silica $(254.42 \pm 13.38)$ group, while the lowest tensile bond strength value was seen in the control $(198.24 \pm 15.32)$ group. It was found that tensile bond strength values were statistically significantly increased in all surface treatment groups. $(p<0,5)$

Conclision: The bonding between the different sand particles applied on both the implant-abutment and the implant abutment-metal substructure showed significant differences.

Keywords: Titanium implant abutment, $30 \mu \mathrm{m}$ silica, $\mathrm{Al}_{2} \mathrm{O}_{3}$ airborne-particle abrasion, resin cement, tensile bond strength test, scanning electron microscope.

\footnotetext{
* Erzincan Binali Yıldırım Üniversitesi Diş Hekimliği Fakültesi Protetik Diş Tedavisi A.D.

** Akdeniz Üniversitesi Diş Hekimliği Fakültesi Protetik Diș Tedavisi A.D.

Kaynakça Bilgisi: Akar T, Kırmalı Ö. Farklı çaplardaki kum partikülleri ile yapılan kumlama işleminin implant-abutment-rezin siman bağlanmasına etkisinin çekme bağlanma testi ile değerlendirilmesi . Atatürk Üniv Diş Hek Fak Derg 2021; 31: 402-7.

Citation Information: Akar T, Kirmali $O$. Evaluation of the effect of sandblasting with different sand particles on the bonding of Implant, abutment and resin cement by tensile bond strenght. J Dent Fac Atatürk Uni 2021; 31: 402-7.
} 


\section{GİRİŞ}

Kısmi dişsiz, tam dişsiz ve özellikle tek diş eksikliği olan vakalarda implant tedavisi yüksek başarı oranı ile fazlaca tercih edilmektedir. İmplant üstü restorasyonlarda implant-dayanak tasarımına göre klinik başarıyı sağlamada vidalı veya simante tutuculu restorasyonlar tercih edilmektedir ancak birbirlerine göre üstünlüklerinde hala tartışmalar bulunmaktadır. ${ }^{1}$ Vidalı implant üstü restorasyonların; komplikasyon sonrasında kolay sökülebilirliği, daha iyi marjinal uyumu, tedarik kolaylığı gibi avantajları mevcutken; açılı yerleştirilen implantlar sebebiyle estetik problemler, vida gevşemesi veya kırılması, ekonomik olarak pahalı olması gibi dezavantajları da bulunmaktadır. Buna karşın simante implant üstü sabit protezlerin daha kolay laboratuvar prosedürleri bulunmaktadır. İlave olarak daha kolay pasif yükleme ve daha az teknik hassasiyet gerektirir. ${ }^{2}$ En büyük dezavantaj ise taşan siman artıkları sonucunda oluşan periimplantitis vakalarıdır. Simante implant üzeri sabit protezler hem geçici hem de daimi olarak simante edilebilirken, en önemli başarı kriteri implant dayanak ve kuron arasındaki bağdır. ${ }^{3}$

Günümüz implant sistemlerinin çoğu, üzerine üst yapıların yapıştırılabileceği implant dayanaklara sahiptir. Bu şekilde doğru temasların oluşturulabilmesi, estetiğin geliştirilebilmesi ve doğru yükleme özelliklerinin uygulanabilmesi sağlanmış olunur. İmplant dayanak hazırlama tasarımları ve simantasyon teknikleri artık doğal dişler için geleneksel sabit protez prosedürlerini taklit etmektedir. Ayrıca kuron ve implant dayanak arasında bulunan siman boşluğu, protezin uyumundaki küçük farklılıkları telafi etmeye yardımcı olabilir. ${ }^{4,5}$

Titanyumun bir protez üst yapı olarak kullanılması, ağız ortamındaki çeşitli zorluklara direnmek için, titanyuma güçlü ve dayanıklı bir siman bağlanmasını gerektirir.6,7 Konvansiyonel simante tutuculu restorasyonların retansiyonu ve direnci çeşitli faktörler tarafından etkilenir.8,9 döküm alt yapının implant dayanağa göre adaptasyonu, ${ }^{10}$ dökümün iç yüzey özellikleri, ve çoklu birimlerin splintlenmesi simantasyon için ne kadar önemli ise de, implant dayanak yüzey alanı ve yüksekliği, ${ }^{11}$ yüzey kalitesi veya pürüzlülük düzeyi de bir o kadar başarı için gerekli faktörlerdir. Özetle başarılı bir simantasyonda hem mikro mekanik kenetleme hem de fizikokimyasal bağlanma gereklidir. ${ }^{12}$

Materyalin ıslanabilirlik özelliklerini geliştirdiği araştırmacılar tarafından kabul edilen en etkili mikromekanik yöntemler, frez ile yüzeyin pürüzlendirmesi ve
$\mathrm{Al}_{2} \mathrm{O}_{3}$ kumlamadır. Yüzeyin temizlenebilirliği ile beraber yüzey pürüzlülüğü artırılarak güçlü bir simantasyon elde edilmektedir. Metal primerler 10-metakriloiloksidesil-dihidrojen fosfat (MDP), 4-metakriloksietil trimellitat anhidrit (4-META) ve aktif monomerler içerir. Böylece metal yüzeyde bulunan oksitlerle kimyasal olarak reaksiyona girer. ${ }^{13}$ Silanlar ise reçine matrisi ve metal yüzey arasında kimyasal bir bağ kurar. ${ }^{14}$ Hem mikromekanik tutmayı hem de kimyasal bağlanmayı başarmak için bilinen bir diğer yöntem, silika ile modifiye edilmiş $\mathrm{Al}_{2} \mathrm{O}_{3}$ parçacıklarıyla kumlama işlemi, yani tribokimyasal silika kaplamadır. Aşındırıcı kum, silan, ışıkla sertleştirilmiş bir bağlama simanı ve bir opak rezinden oluşur. Bu yüzey işlemi, mikromekanik ve kimyasal yapışmanın bir kombinasyonunu sağlar. ${ }^{15-17}$

Yapılan çalışmalarda, araştırmacılar yüzey pürüzlülüğünün retansiyonunun \%31 oranında arttırdığını söylemişlerdir. ${ }^{18}$ Yüzey pürüzlülüğünün artması için yapılan prosedürlerle ilgili çalışmalar ise literatürde az sayıda bulunmaktadır. ${ }^{19}$

Literatürde implant dayanak-rezin siman bağlanmasını farklı mikromekanik yüzey işlemleri ile araştıran çeşitli çalışmalar bulunsa da doğru parametrenin ve prosedürün ne olduğu ile ilgili çelişkili raporlar bulunmaktadır. Yapışma mukavemetini artıran birçok farklı yüzey işleme tekniğinin olduğu çeşitli araştırmalarda belirtilmiştir. ${ }^{15-17-20}$ En etkili ve anlamlı sonuçların kumlama yüzey işlemleri ile olduğu birçok çalışmada rapor edilmiştir. Ancak kullanılan kum partikül boyutunun elde edilecek mikro mekanik bağlanma başarısında ne derece değişkenlik sağlandığına dair bilgi azdır. Bu çerçevede bu çalışma farklı çaplarda kum taneleri ile gerçekleştirilen kumlama işleminin implant dayanakrezin siman bağlanmasına etkisini araştırmayı amaçlamıştır. Çalışmanın sıfır hipotezi kum partikül boyutu artıkça implant dayanak- rezin siman bağlanması bozulabilir.

\section{MATERYAL ve METOD}

Çalışmamızda 40 adet titanyum implant dayanak (5,1 mm. çapında ve $4 \mathrm{~mm}$. yüksekliğinde; Astra Tech $A B$, Mo 'Indahl, Sweden) ve plastik döküm parçası kullanıldı. Her bir implant dayanak ayrı ayrı analoglara vidalanarak $24 \mathrm{~N} / \mathrm{cm}^{\prime}$ ye kadar torklandıktan sonra analogları ile vidalanan implant dayanaklar, önceden tedarik edilen ve çekme bağlanma testinin uygulanacağı cihaza uygun bir şekilde yerleşebilen silindir şeklindeki metal kalıplar içerisine, basamakları yüzeyde 
kalacak şekilde, üretici firmanın tavsiyeleri doğrultusunda otopolimerizan akrilik kalıba (Meliodent, Heraus Kulzer Gmbh, Hanau, Almanya) gömüldü. Böylece tüm örnekler kumlama işlemine hazır bir hale getirildi. Hazırlanan implant dayanaklar farklı yüzey hazırlıklarına tabi tutulmak üzere her grupta 10 adet örnek bulunacak şekilde rastgele 4 gruba ayrıldı $(n=10)$;

Grup 1: Hiçbir yüzey işlemi uygulanmayan grup (Kontrol grubu).

Grup 2: Tribokimyasal silika kaplama grubudur. İmplant dayanaklar $30 \mu \mathrm{m}$ silika kaplı $\mathrm{Al}_{2} \mathrm{O}_{3}$ partikülleri ile $10 \mathrm{~mm}$. mesafeden kumlama cihazı kullanılarak (CoJetTM System; 3M ESPE, Neuss, Almanya) 2,3 bar basınç altında 20 saniye süre ile pürüzlendirildi. Yüzey işlemi sonrası bağlanma yüzeyine silan uygulandı (ESPE ${ }^{\text {TM }}$ SİL, 3M ESPE, Seefeld, Germany). Ardından silan 5 dakika kurumaya bırakıldı ve yüzeyin kontamine olması engellendi.

Grup 3: Örneklere 2,3 bar hava basıncı altında $10 \mathrm{~mm}$. mesafeden 20 saniye süreyle kumlama cihazı (CoJetTM System; 3M ESPE, Neuss, Almanya) yardımıyla $50 \mu \mathrm{m} . \mathrm{Al}_{2} \mathrm{O}_{3}$ partikülleri püskürtüldü.

Grup 4: Örneklere 2,3 bar hava basıncı altında $10 \mathrm{~mm}$. mesafeden 20 saniye süreyle kumlama cihazı yardımıyla $110 \mu \mathrm{m} . \mathrm{Al}_{2} \mathrm{O}_{3}$ partikülleri püskürtüldü.

Yüzey işlemlerini takiben tüm gruplardaki örnekler ultrasonik temizleyicide temizlendi ve kurutuldu.Her bir gruptan rastgele alınan birer örneğin yüzey topografyası, SEM (JSM-6060LV; JEOL, Tokyo, Japan) altında $(\times 1000)$ büyütmede değerlendirildi. Daha sonra implant dayanakların üzerine simante edilecek olan metal altyapılar, üretici firmanın plastik döküm kopinglerinin üst kısmına, çekme bağlanma testini uygulayabilmek için halka şeklinde modelasyonlar eklenerek döküm işlemi ile elde edildi. Döküm işleminin ardından implant dayanaklar ile simante edilecek olan alt yap metallerinin uyumları tek tek kontrol edildi. Daha sonra bütün implant dayanak örnekler üretici firmanın tavsiyesi doğrultusunda rezin siman (Grandio Core Dual Cure; vOCO GmbH, Cuxhaven, Almanya) ile döküm alt yapılara 20 saniye süre ışın gücü 580 mW/ $\mathrm{cm}^{2}$ olan LED ışın cihazı (Bluephase, Ivoclar-Vivadent, Liechtenstein) ile simantasyonları gerçekleştirildi. Taşan siman artıkları dikkatlice temizlenerek uzaklaştırıldı. Tüm örnekler çekme bağlanma testi öncesinde $5^{\circ} \mathrm{C}-55^{\circ} \mathrm{C}$ aralığında 500 devir termal siklusa tabi tutuldu. Çekme bağlanma testleri ise implant dayanaklar ile metal alt yapılar arasındaki bağlantı kopana kadar 0,5 mm./dak. kafa hızında geleneksel test cihazında (Llyod LF Plus, Ametek, Inc.; Lloyod Instruments, İngiltere) gerçekleştirilip değerler Newtona çevirildi. Kopma sonucu oluşan kırık yüzeyle- rin tipleri stereo mikroskopta (Stem: DV4; Zeiss Almanya) (×32) büyütmede; adeziv, koheziv ve kombine olarak sınıflandırıldı. Çalışmaya ait verilerin istatistiksel analizi SPSS paket programı SPSS 13.0 (SPSS for Windows; SPSS, Inc.) kullanılarak yapıldı. Verilerin normal dağıımı Shapiro Wilk testi ile değer- lendirildi ve normal dağılım gösteren verilere tek yönlü varyans analizi (ANOVA) yapılarak gruplar arası farklar değerlendirildi (Tablo 1). ANOVA sonuçlarına göre gruplar arası fark anlamlı bulunduğundan karşılaştır- malar Tukey HSD testi ile yapıldı. İstatistiksel anlamlılık düzeyi $(a=0,05)$ olarak kabul edildi.

Tablo 1. Tek yönlü varyans analizi (ANOVA) sonuçları.

\begin{tabular}{|llll|}
\hline & Df & F & Sig. \\
\hline Gruplar arasında & 5926,04 & 14.648 &, 000 \\
\hline Gruplar içinde & 404,55 & & \\
\hline Total & & & \\
\hline${ }^{*} \mathrm{p}<0,01$ istatistiksel anlamlılığ gösterir. & & \\
\hline
\end{tabular}

\section{BULGULAR}

Çalışmanın sonuçlarına göre en yüksek çekme bağlanma dayanımı değerleri CoJet $30 \mu \mathrm{m}$ grubunda $(254,42 \pm 13,38)$ N gözlenirken, en düşük çekme bağlanma dayanımı değerleri kontrol grubunda (198,24 $\pm 15,32$ ) N gözlendi. Yüzey işlemi yapılan tüm gruplar ile kontrol grubu arasında istatistiksel olarak anlamlı farklar bulundu. $(p<0,5)$ Farklı kum partiküllerinin uygulandığı deney grupları (CoJet $30 \mu \mathrm{m}$, Kumlama 50 $\mu \mathrm{m}$ ve Kumlama $110 \mu \mathrm{m}$ ) kontrol grubu ile karşılaştırıldığında, implant dayanak-siman çekme bağlanma değerlerini artırırken, deney grupları arasında istatistiksel olarak anlamlı fark bulunamadı.

Çekme bağlama dayanımı testi sonrası kırıma tipleri stereo mikroskop altında incelendi ve kontrol grubu dışındaki tüm yüzey işlemi gruplarında implant dayanak etrafında bütün yüzeyi örtmüş rezin siman gözlendi. Çekme bağlanma dayanımı değerlerine paralel olarak kumlama gruplarında bütün örneklerde metal alt yapı iç yüzeyinde az, implant dayanak yüzeyinde yaygın rezin siman izlendi (adeziv-koheziv kopma). Kontrol grubunda ise bütün örneklerde metal alt yapı içerisinde yaygın rezin siman gözlendi (adeziv kopma).

Tarama elektron mikroskobu ile yüzey topografyası incelendiğinde kumlama işlemi yapılan gruplarda yüzeyde yaygın pürüzlü alanlar izlendi (Şekil 1). 30 
$\mu m^{\prime}$ lik silika parçacıkları implant dayanak yüzeyine gömülmüş bir şekilde gözlendi. Kum partikül boyutuna paralel olarak yüzeyde daha küçük girinti alanları izlenirken, kontrol grubunda implant dayanak yüzeyi parlak pürüzsüz bir şeklide gözlendi. Tarama elektron mikroskop ve kırılma tipleri verileri çekme bağlanma dayanımı değerleri ile paralellik göstermiştir.

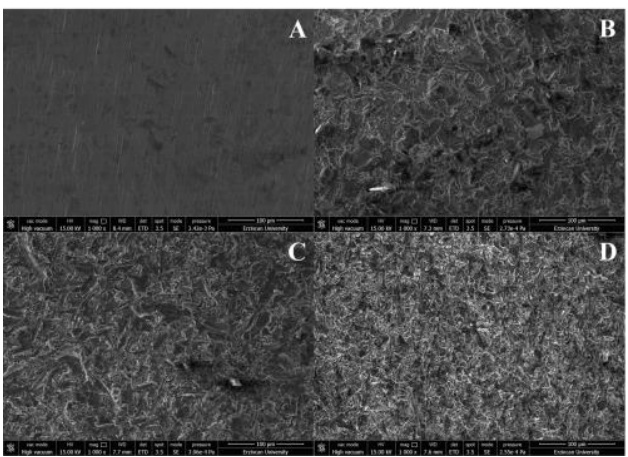

Şekil 1: Bütün gruplardan elde edilen SEM görüntüsü A: Grup 1, B: Grup 2, C: Grup 3, D: Grup 4

\section{TARTIŞMA}

İmplant dayanak-rezin siman bağlanmasına farklı kum partikül boyutlarının etkisini araştırdığımız bu çalışmanın sonuçlarına göre, kumlama gruplarında, kontrol grubuna göre bağlanma dayanımı değerlerinin istatistiksel olarak arttığı bulunmuştur. Bu nedenle sıfır hipotez reddedilmiştir.

Restorasyonların ve dişlerin extraoral değerlendirilmelerinde kullanılan en önemli test yöntemlerinden birisi termal siklustur. Klinik uygulamalar zaman alıcı ve pahalı olduklarından, bu uygulamaların laboratuvar simülasyonlarını gerçekleştirmek daha paratik ve akılcıdır ki termal siklus, bu simülasyonlarda temsil edilen in vitro işlemlerden birisidir. ${ }^{21,22}$

Termal siklus sırasında örneklerin bir kez soğuk, bir kez de sıcak suya daldırılması işlemine "devir", bu sırada geçen toplam süreye "devir süresi" denilmektedir. Devir sayısı 500 ile 50.000 devir arasında, devir süresi ise ortalama 15-60 saniyedir. Soğuk sudan sıcak suya geçiş süresi 5-10 saniye aralığındadır. Termal siklusta ağız içindeki ısı değişimini taklit edecek şekilde en düşük sıcaklık $6,6{ }^{\circ} \mathrm{C}\left(0-36{ }^{\circ} \mathrm{C}\right.$ aralığında), en yüksek sıcaklık değeri 55.5 0C (40-100 0C aralığında) aralığındadır. Birçok çalışmada ise $5-55{ }^{\circ} \mathrm{C}$ kullanılmaktadır. ${ }^{21-23-24}$

İmplant dayanak ile rezin siman bağlantısını arttırmak, özellikle kısa implant dayanağa sahip implant üstü kron ve köprü protezlerde görülen klinik desimantasyonun olumsuz durumunun önüne geçmek için literatürde birçok farklı yüzey işlemi kumlama ${ }^{14,25}$, tribokimyasal silika ${ }^{17}$, lazer ${ }^{2}$, atmosferik plazma kaplama26 araştırmacılar tarafından uygulanmıştır. Yüzey işlemlerinin birbirlerine göre etkinliğine dair çelişkili sonuçlar bildirilmiştir. Kumlama işlemi mikro mekanik bağlantı için gerekli yüzey pürüzlülüğünü elde etmede en etkili ve sıklıkla kullanılan yöntemdir. Ayrıca pürüzlü bir alan elde edilmesinin yanında kumlama işlemi ile yüzeyin temizlenmesi de simantasyon öncesi avantaj sağlamaktadır.27,28 Kumlama sonrası materyal yüzeyinde yüzey pürüzlülüğü elde edilerek yüzey alanı arttırılmış böylece başarılı simantasyon için gerekli olan ıslanabilirlikte sağlanmıştır. ${ }^{29}$ Literatürde 25-250 $\mu \mathrm{m}$ arasında kum partikülü içeren $\mathrm{Al}_{2} \mathrm{O}_{3}$ kumlama işlemi implant dayanak yüzey işlemi olarak uygulanmış, hangi partikül boyutunun implant dayanak-rezin siman bağlanmasında etkili olduğu ile ilgili çelişkili sonuçlar bildirilmiştir. Sahu ve ark. ve Ates ve ark. ${ }^{28,30} 110-125$ um kumlamanın implant dayanak-rezin siman bağlanmasını arttırdığını öte yandan El-Helbawy ve Kırmalı ve ark. ${ }^{2,31} 50 \mu \mathrm{m} \mathrm{Al}_{2} \mathrm{O}_{3}$ kumlamanın implant dayanak-rezin siman bağlanmasında klinik olarak uygulamanın kolay olması ve çekme bağlanma dayanımı değerlerini arttırmasından dolayı etkili bir yöntem olduğunu ifade etmişlerdir. Bunların aksine Akın ve ark. kumlama işleminin implant dayanak yüzeyini bozduğunu ve mekanik bağlanmayı zayıflattığını rapor etmişlerdir. ${ }^{25} \mathrm{Bu}$ çalışma- nın sonuçları da araştırmacıların çalışmalarına benzer şekilde 50-110 $\mu \mathrm{m} \mathrm{Al}_{2} \mathrm{O}_{3}$ kumlamanın implant dayanak-rezin siman bağlanmasını istatistiksel olarak anlamlı derecede arttırdığını göstermektedir. Tarama elektron mikroskobu görüntüleri incelendiğinde kontrol grubuna nazaran 50-110 $\mu \mathrm{m} \mathrm{Al}_{2} \mathrm{O}_{3}$ kumlama gruplarında implant dayanak yüzeyinde retantif alanlar izlendi. Kum partikül boyutunun küçük olması yüzeyde belirgin girinti alanlarının gözlenmesini sağladı. $110 \mu \mathrm{m}$ $\mathrm{Al}_{2} \mathrm{O}_{3}$ kumlama grubunda ise partikül boyutunun

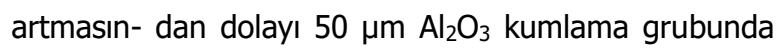
gözlenen girinti alanlarının daha az olduğu saptandı. Çekme bağlanma dayanımı değerleri karşılaştırıldığında ise yüzeydeki bu girinti alanlarının kopma değerleri üzerine etkisinin olmadığı benzer bağlanma dayanımı değerleri gösterdikleri saptandı.

Öte yandan gerek mikro mekanik bağlantı gerek kimyasal bağlantıyı sağlayabilmek için kullanılan en etkili yöntem silika ile modifiye edilmiş $\mathrm{Al}_{2} \mathrm{O}_{3}$ parçaları ile aşındırma yani tribokimyasal silika kaplamadır.7,15,16 $\mathrm{Bu}$ çalışmanın sonuçları $30 \mu \mathrm{m}$ silika kaplı $\mathrm{Al}_{2} \mathrm{O}_{3}$ partikülleri ile kumlama grubunda çekme bağlanma dayanımı değerlerinin kontrol ve diğer kumlama gruplarına

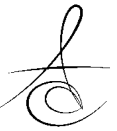


göre daha yüksek olduğunu bulmuştur. Silika kaplama grubu ile $50 \mu \mathrm{m}$ ve $110 \mu \mathrm{m}$ kumlama grupları çekme bağlanma dayanımı değerleri arasında istatiksel olarak anlamlı fark bulunmamıştır. Flipedeoliveria ${ }^{14}$, farklı kum partiküllerini içeren $\mathrm{Al}_{2} \mathrm{O}_{3}$ kumlama işlemlerini implant dayanak yüzeyine uygulamış, farklı simanlar ile bağlanma dayanımını değerlendirmiştir. Kumlama ile beraber silan uygulamasının bağlanma dayanımı değerlerini uygulanmayan gruplara göre arttırdığını, en yüksek bağlanma dayanımı değerlerinin de tribokimyasal silika kaplama gruplarında olduğunu bildirmişlerdir. Mikro mekanik retansiyon ile beraber kimyasal bağlanmanın da ne kadar önemli olduğu bu çalışmanın sonuçları ile söylenebilir. Şeker ve arkadaşları ${ }^{17} 110 \mu \mathrm{m} \mathrm{Al} \mathrm{O}_{3}$ ve $\mathrm{SiO}_{2}$ uyguladıkları implant-dayanak yüzeyinde bu çalışmanın sonuçlarına benzer şekilde tarama elektron mikroskop görüntülerinde derin boşluklar içerisinde mikro boşluklar ve çukurlar oluştuğunu bunların da rezin siman bağlanmasını arttırdığını raporlamışlardır. Bu çalışmada COJET $30 \mu \mathrm{m}$ kaplama uygulanan grupta yüzeyde silisyum parçaları gömülü olduğu bunlarında kimyasal bağlanma için zemin oluşturduğu ve çekme bağlanma dayanımı değerlerinin kumlama gruplarına göre daha fazla olmasını sağladığı saptanmıştır. ${ }^{32,33}$ Aksine $30 \mu \mathrm{m}$ COJET kumlama ile implant dayanak yüzeyinde $120-250 \mu \mathrm{m} \mathrm{Al}_{2} \mathrm{O}_{3}$ kumlama gruplarına göre daha düşük yüzey pürüzlülüğü oluştuğu bu gruplar ile benzer bağlanma dayanımı değerleri oluştuğu ifade edilmiştir. ${ }^{14}$ Benzer şekilde bu çalışmada da COJET 30 $\mu \mathrm{m}$ grubu ile 50-110 $\mu \mathrm{m} \mathrm{Al}_{2} \mathrm{O}_{3}$ kumlama grupları arasında benzer bağlanma dayanımı değerleri gözlenmiştir. Abi-Rached Fde ve arkadaşları ${ }^{14}$ yaptıkları çalışmada 3 farklı rezin siman kullanmış ve örneklere kesme bağlanma dayanımı testi uygulamıştır. Test düzeneğinin farklılığı hazırlanan implant dayanak örneklerinin disk şeklinde olması bağlanma dayanımı değerlerinde farklı sonuçlar çıkmasına neden olmuş olabilir.

Bu çalışmanın sınırlamaları olarak ağız içi ortamı simüle etmek için uygulanan termal siklus uygulamalarının sayısının az olması, çalışmada sadece bir tür titanyum kullanılması, kumlama işleminin her ne kadar aynı kişi tarafından yapılıyor olsa da standartize edilmesinin zor olması söylenebilir. Farklı kumlama parametrelerinin de simanların bağlanma performansını nasıl etkilediğinin daha iyi anlaşılabilmesi ve titanyumun yüzey işlemleri sonrası mekanik özellikleri (korozyon direnci ve yorulma toleransı) üzerine etkilerinin neler olacağını değerlendirmek amaçlı klinik koşullar altında farklı çalışmalar yapılabilir.

\section{SONUÇLAR}

Çalışmanın sonuçlarına göre;

- Kumlama yüzey işlemi implant dayanak-rezin siman çekme bağlanma dayanımı değerlerini arttırmak- tadır.

- Farklı kum partiküllerine sahip kumlama işlemleri implant dayanak ve rezin siman arasında benzer çekme bağlanma dayanımı değerleri göstermiştir.

Finansal Destek

Yazarlar bu çalışma için finansal destek almadıklarını beyan etmişlerdir. Çıkar Çatışması

Yazarlar çıkar çatışması bildirmemişlerdir.

\section{KAYNAKLAR}

1. Shadid R, Sadaqa N. A comparison between screwand cement-retained implant prostheses. A literature review. J Oral Implantol 2012; 38:298-307

2. Ustun O, Akar T, Kirmali O. A Comparative Study of Laser Irradiation Versus Sandblasting in Improving the Bond Strength of Titanium Abutments. Photobiomodul Photomed Laser Surg 2019; 37: 465-72.

3. Sheets JL, Wilcox C, Wilwerding T. Cement selection for cement-retained crown technique with dental implants. J Prosthodont 2008;17:92-6.

4. Guichet DL, Caputo AA, Choi H, et al: Passivity of fit and marginal opening in screw- or cementretained implant fixed partial denture designs. Int J Oral Maxillofac Implants 2000;15:239-46.

5. Campagni WV, Preston JD, Reisbick $\mathrm{MH}$ : Measurements of paint-on die spacers used for casting relief. J Prosthet Dent 1982;47:606-11.

6. Berg E, Davik G, Hegdahl T, Gjerdet NR. Hardness, strength, and ductility of prefabricated titanium rods used in the manufacture of spark erosion crowns. J Prosthet Dent 1996;75: 419-25.

7. Bertolotti RL. Adhesion to porcelain and metal. Dent Clin North Am 2007;51:433-51.

8. Jorgensen KD: The relationship between retention and convergence angle in cemented veneer crowns. Acta Odontol Scand 1955;13:35-40.

9. Kaufman EG, Coelho DH, Colin L: Factors influencing the retention of cemented gold castings. J Prosthet Dent 1961; 11:487-502.

10. Hebel KS, Gajjar RC: Cement-retained versus screw-retained implant restorations: Achieving optimal occlusion and esthetics in implant dentistry. J Prosthet Dent 1997;77:28-35.

11. Goodacre CJ, Kan JY, Rungcharassaeng K: Clinical complications of osseointegrated implants. J Prosthet Dent 1999; 81:537-52. 
12. Bernal G, Okamura M, Muñoz CA. The effects of abutment taper, length and cement type on resistance to dislodgement of cement-retained, implant-supported restorations. J Prosthodont 2003; 12:111-5.

13. Taira $\mathrm{Y}$, Matsumura $\mathrm{H}$, Yoshida $\mathrm{K}$, Tanaka $\mathrm{T}$, Atsuta M. Adhesive bonding of titanium with a methacrylate-phosphate primer and self-curing adhesive resins. J Oral Rehabil 1995;22:409-12.

14. Abi-Rached Fde O, Fonseca RG, Haneda IG, de Almeida- Júnior $A A$, Adabo $G L$. The effect of different surface treatments on the shear bond strength of luting cements to titanium. J Prosthet Dent 2012;108:370-6.

15. Ozcan M, Pfeiffer P, Nergiz I. A brief history and current status of metal-and ceramic surfaceconditioning concepts for resin bonding in dentistry. Quintessence Int 1998;29:713- 24.

16. Tsuchimoto $Y$, Yoshida $Y$, Takeuchi $M$, Mine A, Yatani H, Tagawa Y, Van Meerbeek B, Suzuki K, Kuboki T. Effect of surface pre-treatment on durability of resin-based cements bonded to titanium. Dent Mater 2006;22:545-52.

17. Seker E, Kilicarslan MA, Deniz ST, Mumcu E, Ozkan P. Effect of atmospheric plasma versus conventional surface treatments on the adhesion capability between self-adhesive resin cement and titanium surface. J Adv Prosthodont 2015; 7:249-56.

18. Chaar MS, Att W, Strub JR. Prosthetic outcome of cement retained implant-supported fixed dental restorations: a systematic review. J Oral Rehabil 2011;38:697-711.

19. Kono A, Fusayama T. Casting shrinkage of onepiece-cast fixed partial dentures. J Prosthet Dent 1969;22:73-83.

20. Emir F, Ayyıldız S, Şahin C. Farklı yüzey bitim işlemlerinin feldspatik porselenin yüzey pürüzlülüğüne etkisi. Atatürk Üniv Diş Hek Fak Derg 2015; 25:353-9.

21. Li H, Burrow MF, Tyas MJ. The effect of thermocycling regimens on the nanoleakage of dentin bonding systems. Dent Mater Offic Public Academy Dent Mater 2002; 18:189-96.

22. Gale MS, Darvell BW. Thermal cycling procedures for laboratory testing of dental restorations. J Dent 1999; 27:89-99.

23. Tanaka T, Kamada K, Matsumura H, Atsuta M. A comparison of water temperatures for thermocycling of metal-bonded resin specimens. J prosthetic dentistry. 1995;74:345-9.

24. Papacchini F, Toledano M, Monticelli F, Osorio R,
Radovic I, Polimeni A, et al. Hydrolytic stability of composite repair bond. Eur J Oral Sci 2007; 115: 417-24.

25. Akin H, Tugut F, Topcuoglu S, Kirmali O. Effects of sandblasting and laser irradiation on shear bond strength of low-fusing porcelain to titanium.J Adhes Dent $2013 ; 15: 55-63$.

26. Degirmenci K, Saridag S. Effect of different surface treatments on the shear bond strength of luting cements used with implant-supported prosthesis: An in vitro study. J Adv Prosthodont 2020; 12:7582.

27. Kurt M, Ku“lu“nk T, Ural C, Kulunk S, Danisxman $S$, Savasx S. The effect of different surface treatments on cementretained implant-supported restorations. J Oral Implantol 2013;39:44-51.

28. Ates SM, Korkmaz FM, Caglar IS, Duymus ZY, Turgut S, Bagis EA. The effect of ultrafast fiber laser application on the bond strength of resin cement to titanium. Lasers Med Sci 2017;32:1121-9.

29. Inan O, Acar A, Halkaci S. Effects of sandblasting and electrical discharge machining on porcelain adherence to cast and machined commercially pure titanium. J Biomed Mater Res B Appl Biomater 2006;78:393-400.

30. Sahu N, Lakshmi N, Azhagarasan NS, Agnihotri Y, Rajan M, Hariharan R. Comparison of the effect of implant abutment surface modifications on retention of implantsupported restoration with a polymer based cement. J Clin Diagn Res 2014; 8: 239-42.

31. El-Helbawy NG, El-Hatery AA, Ahmed $\mathrm{MH}$. Comparison of oxygen plasma treatment and sandblasting of titanium implant-abutment surface on bond strength and surface topography. Int J Oral Maxillofac Implants 2016;31:555-62.

32. Watanabe $T$, Ino $S, O k a d a ~ S$, Katsumata $Y$, Hamano $\mathrm{N}$, Hojo $\mathrm{S}$, et al. Influence of simplified silica coating method on the bonding strength of resin cement to dental alloy. Dent Mater J 2008;27:1620.

33. Cobb DS, Vargas MA, Fridrich TA, Bouschlicher MR. Metal surface treatment: characterization and effect on compositeto- metal bond strength. Oper Dent 2000;25:427-33.

\section{Sorumlu Yazarın Yazışma Adresi Türker Akar \\ Fatih Mahallesi EBYÜ Diş Hekimliği Fakültesi Hastanesi \\ e-mail: turkerakar24@gmail.com}

